Research Article

\title{
Photoelectric Properties of DSSCs Sensitized by Phloxine B and Bromophenol Blue
}

\author{
Penghui Ren, ${ }^{1}$ Yuanzuo Li, ${ }^{1}$ Yuehua Zhang, ${ }^{2}$ Hongshuai Wang, ${ }^{1}$ and Qungui Wang ${ }^{1}$ \\ ${ }^{1}$ College of Science, Northeast Forestry University, Harbin 150040, China \\ ${ }^{2}$ College of Science, Jiamusi University, Jiamusi 154007, China \\ Correspondence should be addressed to Yuanzuo Li; yuanzuo.li@gmail.com and Yuehua Zhang; yuehuazhangjd@sina.cn
}

Received 30 June 2016; Revised 12 September 2016; Accepted 5 October 2016

Academic Editor: Francisco R. Zepeda

Copyright (c) 2016 Penghui Ren et al. This is an open access article distributed under the Creative Commons Attribution License, which permits unrestricted use, distribution, and reproduction in any medium, provided the original work is properly cited.

\begin{abstract}
Phloxine B and bromophenol blue as the sensitizers of dye-sensitized solar cells were investigated via UV-Vis spectra, FT-IR spectra, fluorescence spectra, and current-voltage characteristics. The frontier molecular orbital, vibration analysis, and the first hyperpolarizability were calculated with DFT/6-31G(d). The dipole moment, light harvesting efficiency (LHE), and larger absolute value of driving force of electron injection $\left(\Delta G^{\text {inject }}\right)$ were also discussed. The calculated results were compared with the experimental results of phloxine $\mathrm{B}$ and bromophenol blue. It was found that, compared with bromophenol blue, bigger dipole moment of phloxine $\mathrm{B}$ results in larger open circuit voltage $\left(V_{\mathrm{oc}}\right)$ according to the correlation between dipole moment and $V_{\mathrm{oc}}$. At the same time, for configuration of phloxine $\mathrm{B}$, it has higher LHE and $\Delta G^{\text {inject }}$, which are helpful to enhance the abilities of absorbing sunlight and electron injection. Therefore, higher LHE and $\Delta G^{\text {inject }}$ for phloxine B produced a larger value of $J_{s c}$.
\end{abstract}

\section{Introduction}

With gradually aggravated environmental problem, it is hoped that more energies can be found to replace traditional fossil energy. Solar energy as the clean and renewable source has aroused extensive attention. Since O'Regan and Graetzel [1] developed dye-sensitized solar cells (DSSCs), the phototo-electric conversion efficiency $(\eta)$ of this type of solar cells has achieved 7.1-7.9\%. Due to their friendliness and low cost of production [2-5], more attention has been paid to investigate the relationship between structure and performance and to design new DSSCs.

The band engineering of the solar cells devices is shown in Figure 1, which indicates the complete energy levels of the different materials used on the DSSCs devices. DSSCs have the characteristics of the following five aspects [6-9]: (1) Dye molecules absorb sunlight energy, and they are excited from ground state to excited state. (2) After the dye molecules are excited, the electrons are injected into the conduction band of semiconductor and moved into the conducting glass. (3) The electrons diffuse into the external circuit. (4) The dye molecules in oxidation state are deoxidized by the electrolyte in reduction. (5) The electrolyte in oxidation state is deoxidized after receiving the electron at the conducting glass, thereby completing a cycle.

The DSSCs are mainly composed of a nanocrystalline porous semiconductor electrode-absorbed dye, a counter electrode, and an electrolyte containing iodide and triiodide ions [10]. The dye as a sensitizer plays a key factor in absorbing sunlight and conversion solar energy into electric energy. DSSCs mainly are divided into organic dyes and inorganic dyes [11-13]. Inorganic dyes such as N3 and N719 polypyridine complexes [14] have been used as sensitizer in DSSCs. Although DSSCs of inorganic dyes have provided a relatively high efficiency, there are several shortcomings of using inorganic dyes in DSSCs. For example, some inorganic dyes are considered as resources that are limited in amount, which result in more expensive cost in the field of DSSC. By contraries, organic dyes not only are cheaper, but also have been reported to reach efficiency as high as 9.8\% [15]. Nevertheless, the conversion efficiency $\eta$ of organic dyes was still lower than that of inorganic dyes, and it was not suitable for commercial production in comparison with silicon cell [3]. Torchani et al. [16] studied the henna and mallow (Mloukhya) as the sensitizers of DSSCs. The results showed that the filling factor 


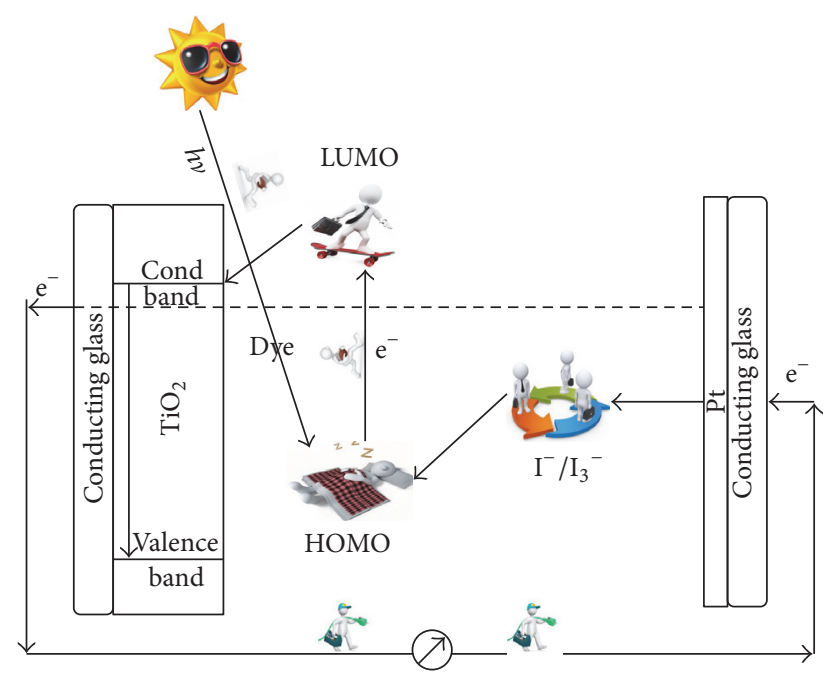

FIGURE 1: Schematic of band edge engineering to electron transfer.

of mallow solar cells is $55 \%$, and $\eta$ is $0.215 \%$. Zhou et al. [17] studied twenty natural dyes, extracted from natural materials (such as flowers, leaves, fruits, traditional Chinese medicines, and beverages), and the results showed that the open circuit voltage and $\eta$ of mangosteen pericarp are the highest, which are $0.686 \mathrm{~V}$ and $1.17 \%$, respectively. Now several organic dyes have been utilized as sensitizers in DSSCs, such as coumarin [18], porphyrins [19-21], triphenylmethane [22, 23], indoline $[24,25]$, and cyanine [26, 27].

In recent years, quantum chemistry method has provided a reliable theoretical basis for the rapid screening of high efficiency dye molecules [28-32]. Kumara et al. [33] reported the black tea waste extract (BTE) as a sensitizer for DSSCs in experimental and theoretical studies. The BTE has four theaflavin analogues, and they are calculated via density functional theory (DFT) and time-dependent density functional theory (TD-DFT). The results showed that theaflavin and theaflavin digallate as sensitizers have well performance among four analogues. Beni and Zarandi [34] analyzed the 3-amino-4-nitrofurazan molecule using functional theory (DFT) and MP2 methods. The geometry of the molecule in the gas phase was optimized and compared with that of the crystal. According to DFT and MP2 methods, they obtain the stable gaseous form. El-Shishtawy et al. [35] studied electronic absorption spectra, ground state geometries, and electronic structures of symmetric and asymmetric squaraine dyes with DFT method, and they found that absorption of squaraine dyes can extend into NIR region by straightforward structural modification, and there are well energy match between dye and $\mathrm{TiO}_{2}$. Sun et al. [36] investigated the optical and electrical properties of two dyes, purpurin and alizarin complexone, as sensitizers by using UV-Vis spectrum, FT-IR spectrum, cyclic voltammetry, $I-V$ characteristics, and DFT calculation, and the results indicated that the side chain has an interesting effect on the optical and electrical properties of sensitizers. Li and coworkers [37] investigated the ground state and excited state properties of polymers BSeTT, QTT, BDT-DTBTBPz $(\mathrm{Pz})$, and BDT-DTBTBQx $(\mathrm{Qx})$ and their derivatives D1, D2, and D3 via DFT and TD-DFT methods, which indicated that the molecule BDT-DTBTBPz and designed molecule (D2) had the best optical and electronic properties among the investigated system. Song et al. [38] reported that electron transfer is a key process of light driven charge separation reaction in organic solar cell.

In this work, phloxine B and bromophenol blue were selected as sensitizers to investigate the optical and electrical properties of DSSCs experimentally, and the UV-Vis spectra, fluorescence spectra, and FT-IR spectra are calculated with density functional theory (DFT) and time-dependent density functional theory (TD-DFT). At the same time, the absorption spectra, infrared spectra, and fluorescence spectra of phloxine B and bromophenol blue are analyzed and compared. In addition, the radiative lifetime $(\tau)$ and total static first hyperpolarizability of the two dyes are calculated. Combined study of experiment and theory provides deep insight into the relationship between structure and performance for two DSSCS.

\section{Methods}

UV-Vis spectra were measured with TU-1900 spectrometer (Beijing, China), and the FT-IR spectra were measured with FT-IR 360 spectrometer (Nicolet, Madison, WI, USA). Solar energy conversion efficiency measurements were done with a solar simulation instrument (Pecell-15, Japan), and light intensity was adjusted via a reference standard Si-solar cell at sunlight intensity of $100 \mathrm{~mW} \mathrm{~cm}^{-2}$. The ground state structures of phloxine $\mathrm{B}$ and bromophenol blue were optimized with DFT [39] using B3LYP [40] functional at the 6-31G(d) basis set. Based on the optimized ground state structures, the highest occupied molecular orbital (HOMO), the lowest unoccupied molecular orbital (LUMO), and energy gaps of the two dye molecules were computed, and vibration frequencies were done at the same level. There was no imaginary vibration frequency in the minimum energy structure in the potential energy landscape. Simulation of absorption spectra was done with TD-DFT at the same level. The total static first hyperpolarizability can be written as follows [41]:

$$
\beta=\sqrt{\beta_{x}^{2}+\beta_{y}^{2}+\beta_{z}^{2}}
$$

Individual static components in the above equation are calculated from

$$
\beta_{i}=\beta_{i i i}+\frac{1}{3} \sum_{i \neq j}\left(\beta_{i j j}+\beta_{j i j}+\beta_{j j i}\right),
$$

where $\beta_{i j k}(i, j, k=x, y, z)$ are tenser components of hyperpolarizability. Due to the Kleinman symmetry, we finally obtain the equation that has been employed:

$$
\begin{aligned}
& \beta_{\mathrm{tot}}=\left[\left(\beta_{x x x}+\beta_{x y y}+\beta_{x z z}\right)^{2}+\left(\beta_{y y y}+\beta_{y z z}+\beta_{y x x}\right)^{2}\right. \\
& \left.+\left(\beta_{z z z}+\beta_{z x x}+\beta_{z y y}\right)^{2}\right]^{1 / 2} .
\end{aligned}
$$

All of the calculations were performed by using Gaussian 09 package [42]. 
<smiles>O=S1(=O)OC(c2cc(Br)c(O)c(Br)c2)(c2cc(Br)c(O)c(Br)c2)c2ccncc21</smiles>

Bromophenol blue<smiles>[NH3+]OC(=O)c1c(Cl)c(Cl)c(Cl)c(Cl)c1-c1c2cc(Br)c(=O)c(Br)c-2oc2c(Br)c(O[NH3+])c(Br)cc12</smiles>

Phloxine B

FIGURE 2: Chemical structures of bromophenol blue and phloxine B.

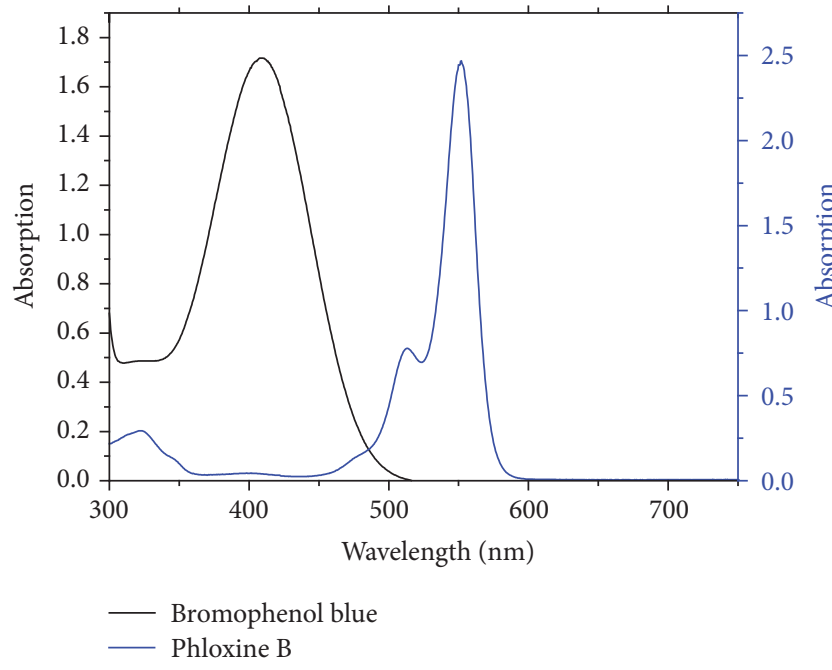

(a)

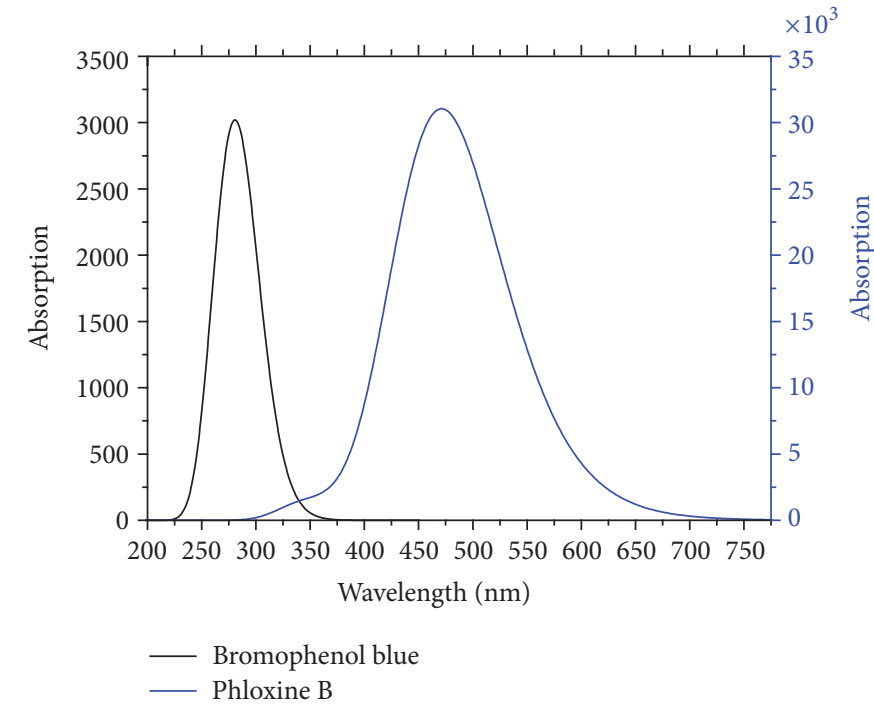

(b)

FigURE 3: (a) Measured UV-Vis absorption spectra of bromophenol blue and phloxine B in experiment. (b) Simulated UV-Vis absorption spectra of bromophenol blue and phloxine B in solvent by using TD-DFT/6-31G(d).

\section{Results and Discussion}

3.1. The Optical Properties of the Dye. The chemical structures of bromophenol blue and phloxine B are shown in Figure 2. The experimental absorption spectra of two dyes in ethanol are presented in Figure 3(a). Absorption spectra of phloxine $B$ showed that the absorption range was $450-600 \mathrm{~nm}$, with maximum absorption peak $\left(\lambda_{\max }\right)$ at around $550 \mathrm{~nm}$. Absorption spectra of bromophenol blue were displayed within the range of $300-500 \mathrm{~nm}$, and $\lambda_{\max }$ was $410 \mathrm{~nm}$, and bromophenol blue had no other obvious absorption peaks (see Figure 3(a)).

In addition, absorption spectra of bromophenol blue and phloxine B were computed via TD-DFT/6-31G(d) in solvent (see Figure 3(b)), and the data are listed in Table 1. Phloxine $\mathrm{B}$ showed the absorption region in $300-700 \mathrm{~nm}$, with a $\lambda_{\max }$ of $472 \mathrm{~nm}$. Bromophenol blue absorption range was 230$330 \mathrm{~nm}$, while $\lambda_{\max }$ was $289 \mathrm{~nm}$. The absorptions in visible and near-UV area were important areas for photovoltaic performance, so there are two important factors (the oscillator strength larger than 0.1 and absorption bands with the wavelength longer than $300 \mathrm{~nm}$ ). The oscillator strength of the first excited state $\mathrm{S} 1$ of phloxine B was 0.7582 (at $472 \mathrm{~nm}$ ), in which the oscillator strength was the strongest among the six excited states. The maximum absorption in absorption spectra was dominated by HOMO $\rightarrow$ LUMO transition (contribution is about 0.70069 ), and the corresponding transition energy was $2.63 \mathrm{eV}$. Meanwhile, for bromophenol blue, at the first excited state S1, the oscillator strength was 0.0322 . The oscillator strength of S1 was the strongest in the states, and this state is composed of HOMO $\rightarrow$ LUMO electron transition.

For more in-depth understanding of the electronic structure of the two dyes, the isodensity plots of the frontier molecular orbitals (MOs) of two dyes were shown in Figure 4. Phloxine B consists of two parts, namely, sodium2,3,4,5-tetrachlorobenzene and sodium-2,4,5,7-tetrabromo6-oxo-xanthen-3-olate, respectively. The electron density of HOMO was located on the sodium-2,4,5,7-tetrabromo-6oxo-xanthen-3-olate group, and that of LUMO was located 
Dye

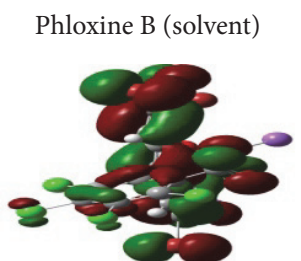

$\mathrm{L}+2$

$\mathrm{L}+1$

$\mathrm{L}$
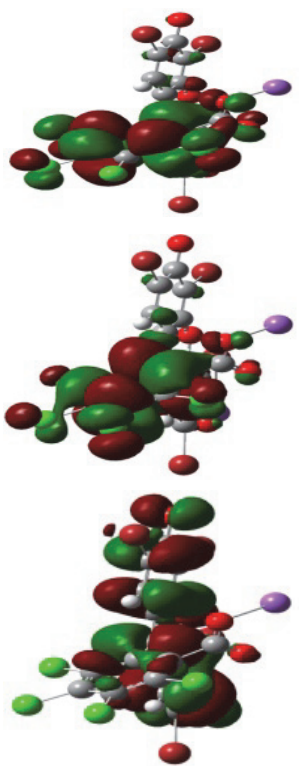

$\mathrm{H}$

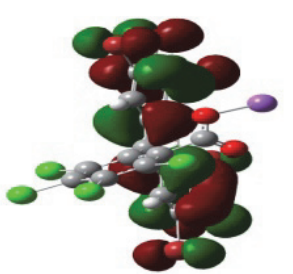

$\mathrm{H}-1$
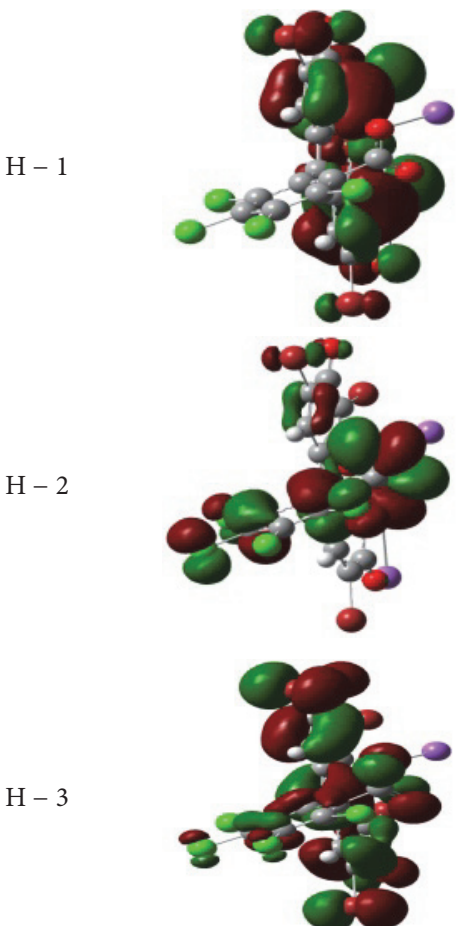

Bromophenol blue (solvent)
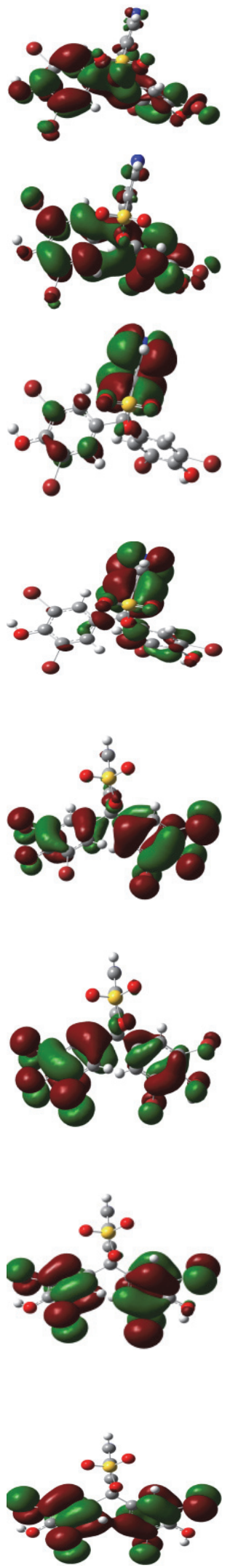

FIGURE 4: Electron densities of the selected HOMO and LUMO of the two dyes. 
TABLE 1: Transition energy and oscillator strength of phloxine B and bromophenol blue in solvent were calculated by using TD-DFT/6-31(d) in the solvent.

\begin{tabular}{|c|c|c|c|c|c|}
\hline Dyes & State & $E(\mathrm{eV})$ & Absorption peak $\lambda(\mathrm{nm})$ & Contribution MO & Strength $f$ \\
\hline \multirow{5}{*}{ Phloxine B } & S1 & 2.63 & 472 & $(0.70069) \mathrm{H} \rightarrow \mathrm{L}$ & 0.7582 \\
\hline & S2 & 3.00 & 413 & $(0.69801) \mathrm{H}-1 \rightarrow \mathrm{L}$ & 0.0187 \\
\hline & S3 & 3.30 & 376 & $(0.49261) \mathrm{H}-4 \rightarrow \mathrm{L}$ & 0.0015 \\
\hline & S4 & 3.32 & 373 & $(0.53756) \mathrm{H}-2 \rightarrow \mathrm{L}$ & 0.0039 \\
\hline & S5 & 3.56 & 349 & $(0.70249) \mathrm{H} \rightarrow \mathrm{L}+1$ & 0.0243 \\
\hline \multirow{7}{*}{ Bromophenol blue } & S6 & 3.64 & 340 & $(0.49354) \mathrm{H} \rightarrow \mathrm{L}+2$ & 0.0079 \\
\hline & $\mathrm{S} 1$ & 4.28 & 289 & $(0.69468) \mathrm{H} \rightarrow \mathrm{L}$ & 0.0322 \\
\hline & S2 & 4.36 & 284 & $(0.69221) \mathrm{H}-1 \rightarrow \mathrm{L}$ & 0.0206 \\
\hline & S3 & 4.53 & 273 & $(0.69343) \mathrm{H} \rightarrow \mathrm{L}+1$ & 0.0021 \\
\hline & S4 & 4.61 & 269 & $(0.52434) \mathrm{H}-1 \rightarrow \mathrm{L}+1$ & 0.0127 \\
\hline & S5 & 4.62 & 231 & $(0.48364) \mathrm{H}-2 \rightarrow \mathrm{L}$ & 0.0148 \\
\hline & S6 & 4.72 & 263 & $(0.60405) \mathrm{H}-3 \rightarrow \mathrm{L}$ & 0.0037 \\
\hline
\end{tabular}

on conjugated bridge and sodium-2,4,5,7-tetrabromo-6-oxoxanthen-3-olate group. From the distribution of the above molecular orbitals of HOMO and LUMO, electron transfer was most likely to occur from sodium-2,4,5,7-tetrabromo-6oxo-xanthen-3-olate group unit to conjugated bridge. Electron densities of other MOs were shown in Figure 4, corresponding to the HOMO - 1, HOMO - 2, HOMO - 3, LUMO +1 , LUMO + 2, and LUMO + 3, respectively.

Bromophenol blue is composed of three parts, namely, two identical 2,6-dibromophenol groups and pyridine, respectively. The electron density of HOMO was located on two identical 2,6-dibromophenol groups and conjugated bridge, and that of LUMO was located on pyridine and conjugated bridge. As the electron transition is from HOMO to LUMO, it was found that a tiny fraction of MOs for HOMO and LUMO was loaded in conjugated bridge, and more electrons were moved to pyridine. Therefore, excitation should result in electron transfer from two identical 2,6-dibromophenol groups to pyridine. The HOMOs and LUMOs in the dyes indicated that the transitions at maximum absorptions had intramolecular charge transfer (ICT) character, and they played an important role in DSSCs.

3.2. Fourier Transforms Infrared Spectra. Fourier transforms infrared (FT-IR) spectra of phloxine B and bromophenol blue were recorded in the $500-4000 \mathrm{~cm}^{-1}$ range using $\mathrm{KBr}$ pellets and calculated at DFT/B3LYP methods with the 6-31G(d) basis set. The experimental FT-IR spectra were shown in Figures 5(a) and 5(b), and calculated FT-IR spectra were given in Figures 5(c) and 5(d). For absorption peak vibration of bromophenol blue, the absorption peaks were distributed in ranges of $1000-2000 \mathrm{~cm}^{-1}$ and $3000-4000 \mathrm{~cm}^{-1}$. They were $1398.75,1472.31,1634.19,3440.26 \mathrm{~cm}^{-1}$, and $3851.47 \mathrm{~cm}^{-1}$ (see Figure 5(a)), respectively. Swing vibration of two C-H bonds of 2,6-dibromophenol group for bromophenol blue was observed at $3243.83 \mathrm{~cm}^{-1}$ (see Figure 5(c)). Swing vibration of two O-H bonds of two 2,6-dibromophenol groups was observed at $1389.36 \mathrm{~cm}^{-1}$. Stretching vibration of two C-H bonds of pyridine group was observed at $1452.16 \mathrm{~cm}^{-1}$ and $3652.02 \mathrm{~cm}^{-1}$, respectively. Pyridine group swing vibration was observed at $1632.13 \mathrm{~cm}^{-1}$.

$\mathrm{C}-\mathrm{H}$ vibrations were studied as follows: $\mathrm{C}-\mathrm{H}$ swing and stretching vibration in unit 2,6-dibromophenol groups were calculated in the range of 681.42, 868.79-934.34, 974.53, 1085.05-1087.63, 1205.43-1209.30, 1232.40, 1333.11-1338.06, $1388-1445.35,1519.36-1609.41$, and $1641.86-1644.21 \mathrm{~cm}^{-1}$ and at $3234.68-3443.83 \mathrm{~cm}^{-1}$. C-H swing and stretching in pyridine group were calculated in range of 718.94, 765.71-766.86, 842.82-863.99, 944.66, 993.54-999.10, 1057.47, 1108.781171.92 , and $1452.16-1513.01 \mathrm{~cm}^{-1}$ and at $3192.57-322.58 \mathrm{~cm}^{-1}$, respectively.

For S-O, OH, and ring vibrations, results showed that $\mathrm{S}-\mathrm{O}$ stretching vibration was observed at $746.58 \mathrm{~cm}^{-1}$, and $\mathrm{S}=\mathrm{O}$ symmetric stretching was observed at 1171.92 and $1357.69 \mathrm{~cm}^{-1}$ in FT-IR, respectively. OH swing and stretching vibration occurred in the range of 613.14, 1205.43-1209.30, 1295.17-1301.14, 1338.06 1388.22-1445.35, 1519.36-1609.41, and $3651.80-3652.02 \mathrm{~cm}^{-1}$. Benzene rings stretching vibration often occurred in range of 718.94-742.42, 766.86, and $1606.85-1641.80 \mathrm{~cm}^{-1}$. Benzene rings twisting vibration was found to be $765.71 \mathrm{~cm}^{-1}$.

For absorption peak vibration of phloxine $\mathrm{B}$, the main absorption peaks of FT-IR spectra focus on $1000-2000 \mathrm{~cm}^{-1}$. They were 1242.93, 1355.36, 1463.41, $1558.18 \mathrm{~cm}^{-1}$, and $1634.31 \mathrm{~cm}^{-1}$ (see Figure 5(b)), respectively. Swing vibration of sodium-2,4,5,7-tetrabromo-6-oxo-xanthen-3-olate group was observed at $1453.18 \mathrm{~cm}^{-1}$ and $1548.97 \mathrm{~cm}^{-1}$ (see Figure $5(\mathrm{~d})$ ), respectively. Two $\mathrm{C}-\mathrm{H}$ bonds' stretching vibrations of sodium-2,4,5,7-tetrabromo-6-oxo-xanthen-3-olate group were observed at $1228.48 \mathrm{~cm}^{-1}$ and $1356.04 \mathrm{~cm}^{-1}$, respectively. $\mathrm{C}=\mathrm{O}$ bond stretching vibration of sodium-2,4,5,7tetrabromo-6-oxo-xanthen-3-olate group was observed at $1642.66 \mathrm{~cm}^{-1}$. 


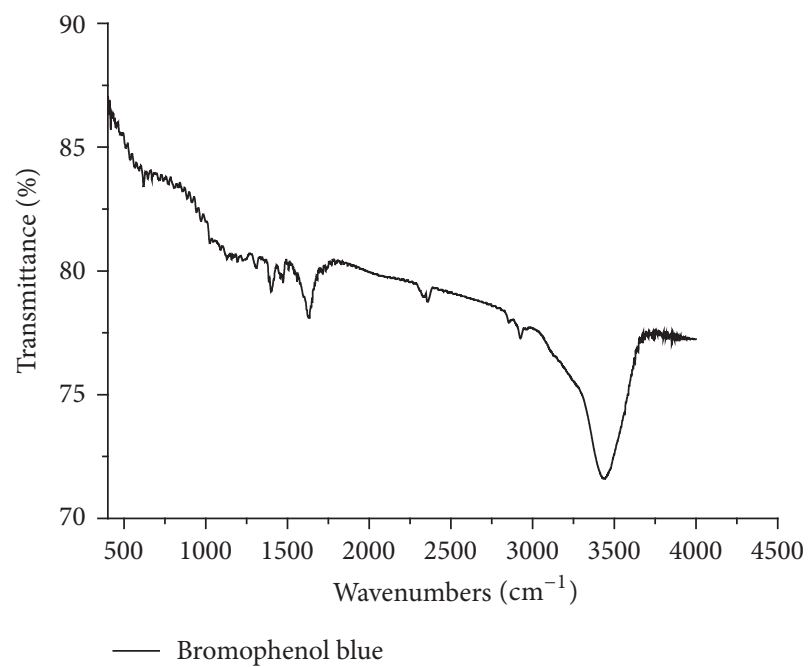

(a)

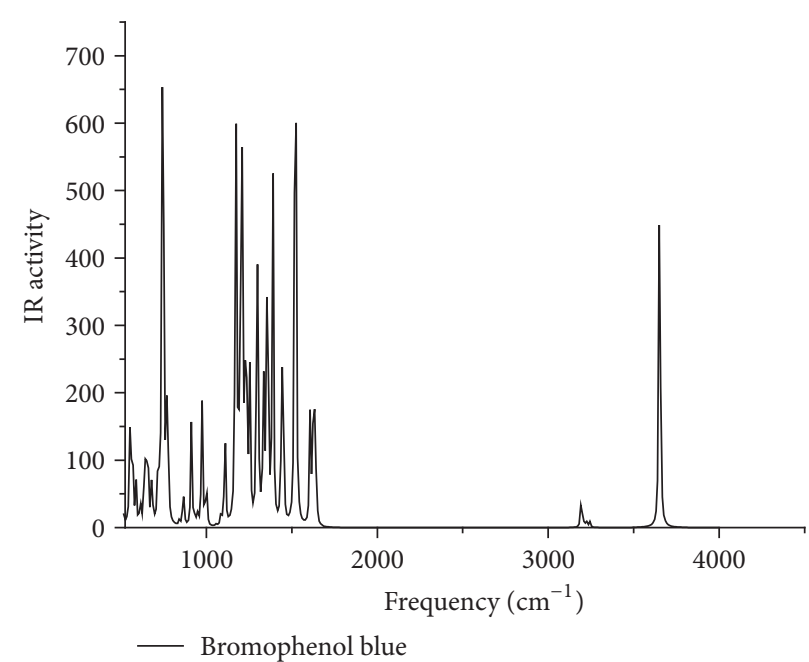

(c)

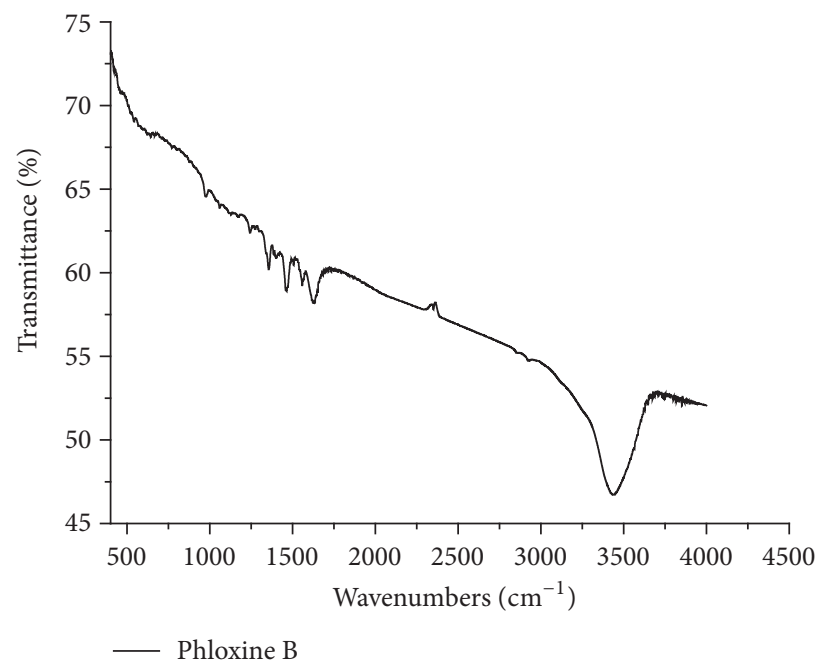

(b)

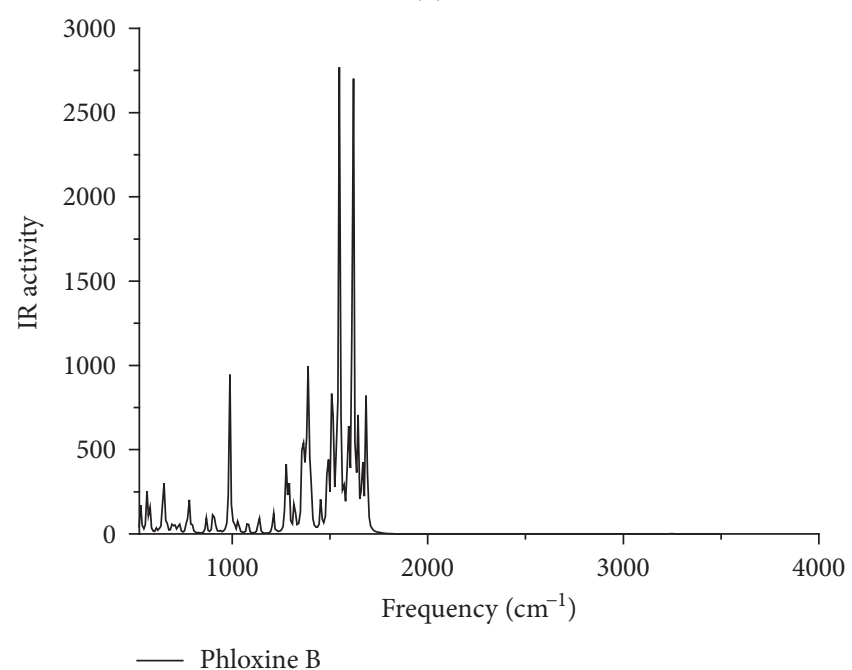

(d)

FIGURE 5: (a) Measured FT-IR spectra of bromophenol blue in experiment. (b) Measured FT-IR spectra of phloxine B in experiment. (c) Simulated IR spectra of bromophenol blue in theory. (d) Simulated IR spectra of phloxine B in theory.

For $\mathrm{C}-\mathrm{H}, \mathrm{COONa}$, and O-Na vibrations, it was found that $\mathrm{C}-\mathrm{H}$ swing and stretching vibration in sodium-2,4,5,7tetrabromo-6-oxo-xanthen-3-olate group were assigned in the region of $936.95,987.30,1008.72,1030.88,1204.51-$ $1511.59,1545.61,1617.78$, and $1665.48 \mathrm{~cm}^{-1}$, respectively. The COONa symmetric stretching vibration of sodium-2,4,5,7tetrabromo-6-oxo-xanthen-3-olate group occurred at 910.95 and $1686.27 \mathrm{~cm}^{-1}$, respectively. O-Na stretching vibration was observed at $1593.03 \mathrm{~cm}^{-1}$.

Furthermore, there are three benzene rings in the phloxine B. Benzene ring symmetric stretching vibration was observed in the region of 910.95-987.30, 1030.88, 1388.10, $1453.18,1532.61$, and $1572.03 \mathrm{~cm}^{-1}$ and at $1665.48 \mathrm{~cm}^{-1}$, respectively. Benzene ring asymmetric stretching vibration was calculated in range of 1008.72, 1136.98-1204.51, $1272.62,1290.53,1356.04,1382.82,1488.37,1511.59$, and $1545.61 \mathrm{~cm}^{-1}$, and in-plane bending vibration was computed at $1211.25 \mathrm{~cm}^{-1}$.
3.3. Photovoltaic Characterization. The following formula is used to calculate the maximum power photo-to-electric conversion efficiency $(\eta)$ [43]:

$$
\eta=\frac{J_{\mathrm{sc}} \cdot V_{\mathrm{oc}} \cdot \mathrm{FF}}{P} .
$$

Here, $P$ was the intensity of the incident light; $J_{\mathrm{sc}}, V_{\mathrm{oc}}$, and FF represent short circuit density, open circuit voltage, and fill factor, respectively.

The FF was defined as the ratio of the maximum power $P_{\max }$ obtained from the DSSCs and the theoretical maximum power of it [44]. Hence,

$$
\mathrm{FF}=\frac{I_{m} \cdot V_{m}}{J_{\mathrm{sc}} \cdot V_{\mathrm{oc}}} .
$$

Here, $I_{m}$ and $V_{m}$ were current and voltage related to the maximum power. In the experiment, we used the phloxine $B$ 


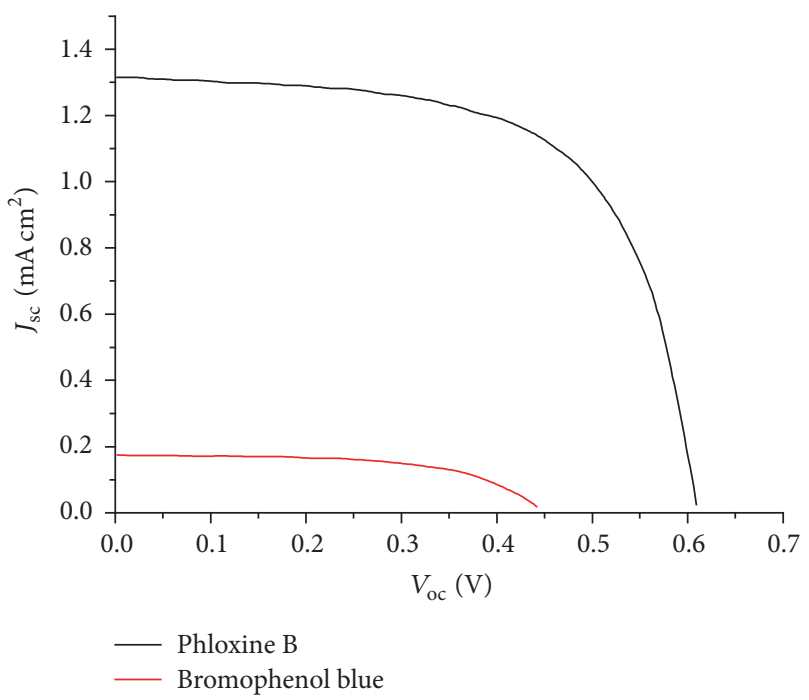

FIGURE 6: The photocurrent-potential $(I-V)$ characteristics of the DSSCs with $\mathrm{TiO}_{2}$ film electrode sensitized by phloxine $\mathrm{B}$ and bromophenol blue.

TABLE 2: Current-voltage characteristics of phloxine B and bromophenol blue.

\begin{tabular}{lcccc}
\hline & $V_{\text {oc }}(\mathrm{V})$ & $J_{\text {sc }}\left(\mathrm{mA} / \mathrm{cm}^{2}\right)$ & FF & $\eta \%$ \\
\hline Phloxine B & 0.61 & 1.31 & 0.65 & 0.52 \\
Bromophenol blue & 0.44 & 0.17 & 0.68 & 0.05 \\
\hline
\end{tabular}

and bromophenol blue as sensitizers, to measure the currentvoltage $(I-V)$ under sunlight intensity of $100 \mathrm{~mW} \mathrm{~cm}^{-2}$. And the results are shown in Figure 6 , and measured $I-V$ characteristics of the DSSCs sensitized for the two dyes are listed in Table 2.

The DSSCs sensitized with phloxine B showed $\eta$ of $0.52 \%$, with $V_{\mathrm{oc}}$ of $0.61 \mathrm{~V}, J_{\mathrm{sc}}$ of $1.31 \mathrm{~mA} \mathrm{~cm}^{-2}$, and FF of 0.65 , while the DSSCs sensitized with bromophenol blue showed $\eta$ of $0.05 \%$, with $V_{\text {oc }}$ of $0.44 \mathrm{~V}, J_{\mathrm{sc}}$ of $0.17 \mathrm{~mA} \mathrm{~cm}^{-2}$, and FF of 0.68 . The results showed that photovoltaic performance of phloxine $\mathrm{B}$ is greater than that of bromophenol blue. Then $V_{\mathrm{oc}}$ of the DSSCs using the phloxine B as sensitizer was more suitable. The photovoltaic performance of the phloxine B was higher than that of bromophenol blue. This improvement in the photovoltaic performance of the DSSCs with phloxine B could be attributed to the absorption spectra of solar radiations (450$600 \mathrm{~nm}$ ) (see Figure 3(a)) [43]. This result indicated that the range of absorption spectra affected $\eta$ of DSSCs.

To analyze the difference of two dyes, we performed theoretical calculation to explain the well photoelectric properties (larger $V_{\mathrm{oc}}$ and $J_{\mathrm{sc}}$ ) of phloxine $\mathrm{B}$. The value of $V_{\text {oc }}$ was viewed as the difference between the quasi-Fermi level of semiconductor conduction band edge value and the electrolyte oxygen reductions. Because the electrolyte was typically $\mathrm{I}^{-} / \mathrm{I}_{3}^{-}$, the redox electrolyte can be considered constant. The value of $V_{\text {oc }}$ has a direct dependence on the shift of the reduction potential of the semiconductor conduction band $\left(\Delta E_{\mathrm{CB}}\right)$, and $\Delta E_{\mathrm{CB}}$ is expressed [45]:

$$
\Delta E_{\mathrm{CB}}=\frac{-q \mu_{\text {normal }} \gamma}{\varepsilon_{0} \varepsilon},
$$

where $\gamma$ is adsorbed on the surface concentration and $\mu_{\text {normal }}$ is the dipole moment component perpendicular to the direction of $\mathrm{TiO}_{2}$ surface (where $\mu_{\text {normal }}$ was the $x$-axis direction), $\varepsilon_{0}$ is the gas permittivity, and $\varepsilon$ is the dielectric constant of the organic monolayer. Obviously, according to (6), the larger the value of $\mu_{\text {normal }}$, the bigger the value of $\Delta E_{\mathrm{CB}}$. The change of $\Delta E_{\mathrm{CB}}$ has direct influence on $V_{\mathrm{oc}}$. In order to analyze and compare $V_{\text {oc }}$, we calculated $\mu_{\text {normal }}$, as shown in Figure 7. $\mu_{\text {normal }}$ of phloxine B was $19.80 \mathrm{D}$, and $\mu_{\text {normal }}$ of bromophenol blue was -1.29 D. $\mu_{\text {normal }}$ of phloxine B was much larger than that of bromophenol blue. Therefore, the increasing $\mu_{\text {normal }}$ for phloxine B results in the larger $V_{\text {oc }}[46,47]$.

For the dye sensitizers, the light harvesting efficiency (LHE) and oscillator strength had correlated relationship [48], which is expressed as follows:

$$
\mathrm{LHE}=1-10^{-f} .
$$

Here, $f$ is the oscillator strength. According to Table 1, we found that the first excited state of phloxine $B$ and bromophenol blue corresponds to a dominant position in absorption, and the oscillator strength of phloxine B was larger than that of bromophenol blue. The LHE of phloxine B was 0.8255 , and that of bromophenol blue was 0.0714 . So the correlated relationship between the oscillator strength and light harvesting efficiency (LHE) implied that the dye with larger oscillator strength made more LHE, and thus phloxine $\mathrm{B}$ has well utilities of sunlight.

The sunlight absorption and electron injection were important process in DSSCs, which obviously affect the efficiency of $J_{\text {sc }}$ [49]. Driving force of electron injection $\left(\Delta G^{\text {inject }}\right)$ means that the excited dye provided electron into semiconductor conduction band. Electron injection occurred from the excited state; $\Delta G^{\text {inject }}$ could be calculated by the following equation [50]:

$$
\Delta G^{\text {inject }}=E_{\mathrm{OX}}^{\text {dye }^{*}}-E_{\mathrm{CB}}^{\mathrm{SC}},
$$

where $E_{\mathrm{OX}}^{\text {dye }}$ is the oxidation potential of the excited state of the dye, and $E_{\mathrm{CB}}^{\mathrm{SC}}$ is the reduction potential of the semiconductor conduction band. The reported $E_{\mathrm{CB}}^{\mathrm{SC}}=4.0 \mathrm{eV}$ [51] for $\mathrm{TiO}_{2}$ was adopted in this work. $E_{\mathrm{OX}}^{\text {dye* }}$ could be calculated as follows [52]:

$$
E_{\mathrm{OX}}^{\text {dye }^{*}}=E_{\mathrm{OX}}^{\text {dye }}-\lambda_{\text {max }}
$$

Here $E_{\mathrm{OX}}^{\text {dye }}$ is the redox potential of the ground state, and $\lambda_{\max }$ was the absorption maximum with ICT character.

The data of phloxine $\mathrm{B}$ and bromophenol blue were listed in Table 3. According to the calculation results, $\Delta G^{\text {inject }}$ of phloxine $\mathrm{B}(-1.82 \mathrm{eV})$ was higher than bromophenol blue $(-1.49 \mathrm{eV})$, meaning that $\Delta G^{\text {inject }}$ of phloxine B was easier than bromophenol blue. $\Delta G^{\text {inject }}$ was an important influence 
Dye

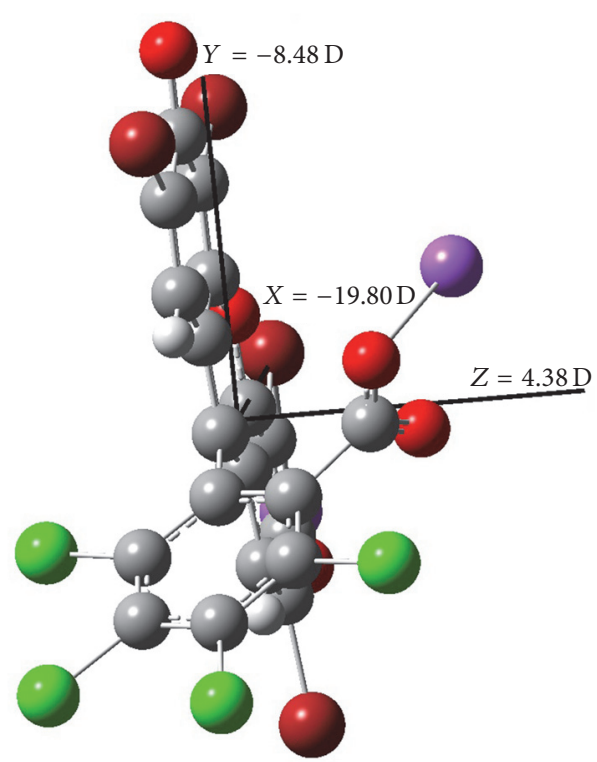

Bromophenol blue

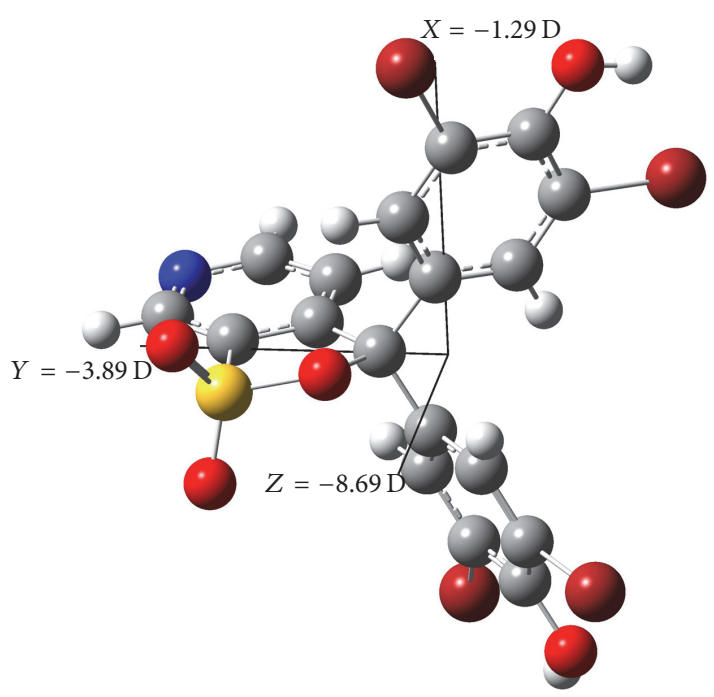

Figure 7: Dipole moment of phloxine B and bromophenol blue (gray for C, deep red for $\mathrm{Br}$, red for O, green for $\mathrm{Cl}$, blue for $\mathrm{N}$, purple for $\mathrm{Na}$, yellow for $\mathrm{S}$, and white for $\mathrm{H}$ ).

TABLE 3: The driving force of electron injection $\Delta G^{\text {inject }}$ (in eV) for the phloxine B and bromophenol blue in the solvent.

\begin{tabular}{llll}
\hline Dye & $E_{\text {OX }}^{\text {dye }}$ & $E_{\text {OX }}^{\text {dye* }}$ & $\Delta G^{\text {inject }}$ \\
\hline Phloxine B & 5.44 & 2.83 & -1.82 \\
Bromophenol blue & 6.63 & 2.35 & -1.49 \\
\hline
\end{tabular}

TABLE 4: Energy levels of HOMO, LUMO, and energy gaps in solvent $(\mathrm{eV})$.

\begin{tabular}{lcc}
\hline & Phloxine B & Bromophenol blue \\
\hline $\mathrm{H}$ & -5.44 & -6.63 \\
$\mathrm{~L}$ & -2.64 & -1.77 \\
Gap & -2.80 & -4.86 \\
\hline
\end{tabular}

factor for the electron injection efficiency. At the same time, the LHE showed that phloxine B was stronger than bromophenol blue, as discussed above. Therefore, phloxine B has improved absorption and injection abilities in comparison with bromophenol blue, which cause the larger value of $J_{\mathrm{sc}}$.

3.4. Ground and Excited State Properties. To ensure that electrons could be effectively injected into the conduction band of $\mathrm{TiO}_{2}$ (about $-4.0 \mathrm{eV}$ ) [51], LUMO energy level must be higher than the edge of the conduction band of the $\mathrm{TiO}_{2}$, and HOMO energy level must be below $\mathrm{I}^{-} / \mathrm{I}_{3}{ }^{-}$electrolyte (about $-4.85 \mathrm{eV}$ ) [46]. Energy levels of MOs and energy gaps in solvent were studied by using DFT/B3LYP/6-31G(d) method. Energy levels and HOMO-LUMO gap are presented in Figure 8, and the calculated data are listed in Table 4. For phloxine $\mathrm{B}$, the highest occupied MO (HOMO) was $-5.44 \mathrm{eV}$ and the lowest unoccupied MO (LUMO) was $-2.64 \mathrm{eV}$. For bromophenol blue, the HOMO was $-6.63 \mathrm{eV}$ and the LUMO

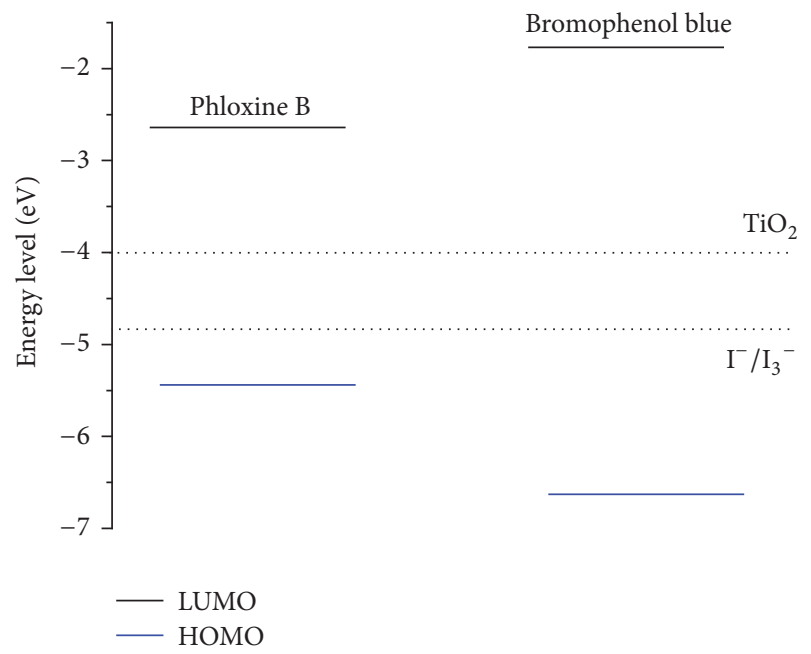

Figure 8: Energy levels of phloxine B and bromophenol blue in solvent.

was $-1.77 \mathrm{eV}$. The band gap of phloxine $\mathrm{B}$ was smaller than that of bromophenol blue, meaning there is a red-shifted absorption for phloxine B. From Figure 8, it seems that the LUMOs of phloxine $\mathrm{B}$ and bromophenol blue were all higher than the conduction band of $\mathrm{TiO}_{2}$, meaning that the electron injection can occur from excited dyes into $\mathrm{TiO}_{2}$, and 
TABLE 5: Hyperpolarizability of phloxine and bromophenol blue.

\begin{tabular}{|c|c|c|c|c|c|c|c|c|c|c|c|}
\hline & $\beta_{x x x}$ & $\beta_{x x y}$ & $\beta_{x y y}$ & $\beta_{y y y}$ & $\beta_{x x z}$ & $\beta_{x y z}$ & $\beta_{y y z}$ & $\beta_{x z z}$ & $\beta_{y z z}$ & $\beta_{z z z}$ & $\beta_{\text {tot }}$ \\
\hline Phloxine B & 1056.816 & 1811.374 & -176.166 & -1358.839 & 303.029 & 103.036 & -151.766 & -220.581 & 194.588 & -334.674 & 942.390 \\
\hline Bromophenol blue & -166.629 & 263.472 & -97.931 & 430.917 & -91.126 & -74.537 & -118.993 & 37.162 & 73.307 & -204.705 & 901.746 \\
\hline
\end{tabular}

TABLE 6: The calculated electron radiative lifetime $(\tau)$ for the phloxine B and bromophenol blue in the solvent.

\begin{tabular}{lcccc}
\hline Dye & $E(\mathrm{eV})$ & $\lambda(\mathrm{nm})$ & Strength $f$ & $\tau(\mathrm{s})$ \\
\hline Phloxine B & 2.45 & 507 & 0.6268 & $6.14 \times 10^{-9}$ \\
Bromophenol blue & 3.22 & 385 & 0.0085 & $2.61 \times 10^{-7}$ \\
\hline
\end{tabular}

the HOMOs of two dyes were lower than $\mathrm{I}^{-} / \mathrm{I}_{3}{ }^{-}$(see Figure 8); therefore, two dyes can obtain electron to recovery.

Molecular nonlinear optical properties have a close relationship with external electric field. It reflects the characteristics of the intramolecular charge transfer (ICT), which can affect the electron injection efficiency and the light current. The first hyperpolarizability $(\beta)$ is directly proportional to the difference in the dipole moment $\left(\Delta \mu_{\mathrm{eg}}\right)$ between the ground state and the excited state and the transition dipole moment $\left(\mu_{\text {eg }}\right)$, and it is inversely proportional to the transition energy. The first hyperpolarizabilities could be written as follows [53]:

$$
\beta \infty \frac{\Delta \mu_{\mathrm{eg}}\left(\mu_{\mathrm{eg}}\right)^{2}}{E_{\mathrm{eg}}^{2}}
$$

where $\Delta \mu_{\text {eg }}$ and $\mu_{\text {eg }}$ are difference in the dipole moment for ground state and excited state and the transition dipole, $E_{\text {eg }}$, is transition energy. The first hyperpolarizabilities were calculated, as listed in Table 5 . The $\beta_{\text {tot }}$ of phloxine $\mathrm{B}$ was higher than that of bromophenol blue. Table 1 and Figure 7 support the results of hyperpolarizabilities. Figure 7 showed that the value of $\mu_{\text {eg }}$ for phloxine $\mathrm{B}$ is larger than that of bromophenol blue; at the same time, phloxine $B$ has smaller excitation energy, so phloxine $\mathrm{B}$ has larger hyperpolarizabilities with obvious ICT.

3.5. Fluorescence Spectroscopy of Dyes. Radiative lifetime $(\tau)$ played an important role in DSSCs, and it could affect charge recombination [54]. $\tau$ could be calculated as follows [55]:

$$
\tau=\frac{a c^{3} u^{2}}{2 f e^{2}} .
$$

Here, $c$ is the speed of light, $f$ is the oscillator strength, and $e$ is the fluorescent energy. The experimental spectra of the phloxine B and bromophenol blue are shown in Figure 9, and the calculated fluorescence maxima $\lambda$, oscillator strength $(f$ in a.u.), and relative radiative lifetime are listed in Table 6. The maximum absorption peak of phloxine B was $507 \mathrm{~nm}$. The fluorescence energy, oscillator strength, and radiative lifetime were $2.45 \mathrm{eV}, 0.6268$, and $6.14 \times 10^{-9} \mathrm{~s}$, respectively. The absorption peak of bromophenol blue was $385 \mathrm{~nm}$. The fluorescence energy, oscillator strength, and radiative lifetime were $3.22 \mathrm{eV}, 0.0085$, and $2.61 \times 10^{-7} \mathrm{~s}$, respectively. The radiative lifetime of bromophenol blue was higher $\left(2.61 \times 10^{-7} \mathrm{~s}\right)$. But phloxine B was propitious to charge recombination [54].

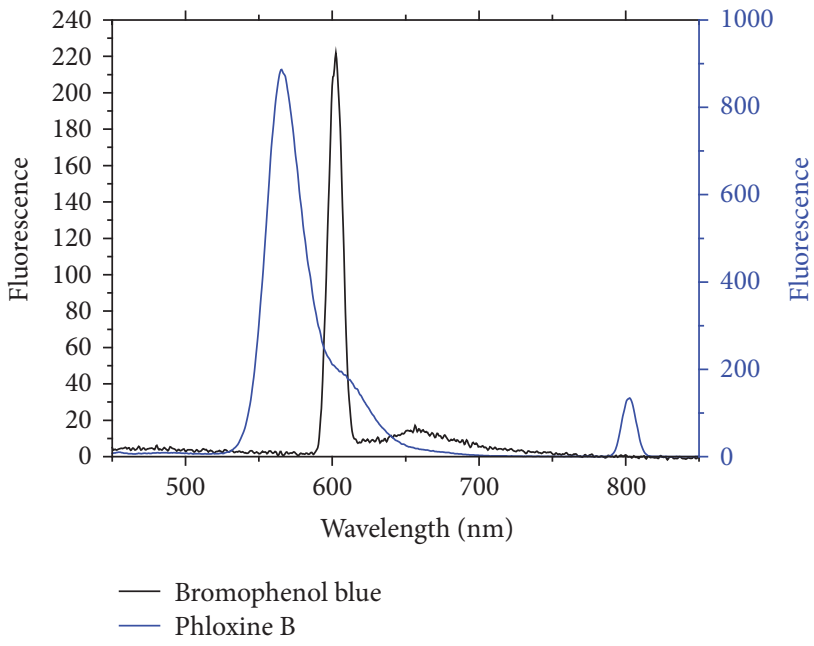

Figure 9: Fluorescence spectra of phloxine B and bromophenol blue.

\section{Conclusion}

The absorption, molecular orbital energies, radiative lifetimes, LHE, and $\Delta G^{\text {inject }}$ were addressed. The oscillator strength (0.7582), vertical dipole moment (19.80 D), and $\Delta G^{\text {inject }}(-1.82 \mathrm{eV})$ for phloxine $\mathrm{B}$ were higher than those of bromophenol blue. The $J_{\mathrm{sc}}, V_{\mathrm{oc}}$, and $\eta$ of phloxine $\mathrm{B}$ were $0.61 \mathrm{~V}, 1.31 \mathrm{~mA} / \mathrm{cm}^{2}$, and $0.52 \%$, respectively, which were higher than those of bromophenol blue. The results showed that higher dipole moment of phloxine $\mathrm{B}$ corresponds to larger $V_{\text {oc }}$. This means that enlarging dipole moment was a possible way to increase $V_{\text {oc }}$ of DSSCs. The larger oscillator strength, higher LHE, and larger absolute value of $\Delta G^{\text {inject }}$ correspond to larger $J_{\text {sc }}$. This means increasing oscillator strength and LHE and larger absolute value of $\Delta G^{\text {inject }}$ were a possible way to increase $J_{\text {sc }}$. A similar trend between theory and experiment was observed. Photovoltaic performance of phloxine B was significantly higher than that of bromophenol blue.

\section{Competing Interests}

The authors declare that they have no competing interests. 


\section{Acknowledgments}

This work was supported by the Fundamental Research Funds for the Central Universities (Grant no. 2572014CB31), the Heilongjiang Provincial Youth Science Foundation (Grant no. QC2013C006), the National Natural Science Foundation of China (Grant nos. 11404055 and 11374353), China Postdoctoral Science Foundation (2016M590270), Heilongjiang Postdoctoral Grant (LBH-Z15002), National Undergraduate Innovative and Entrepreneurial Training Program (Grant no. 201610225099), and Academic Research Training of NEFU for Undergraduate (Grant no. KY2015020).

\section{References}

[1] B. O'Regan and M. Graetzel, "A low-cost, high-efficiency solar cell based on dye-sensitized colloidal titanium dioxide films," Nature, vol. 353, no. 6346, pp. 737-740, 1991.

[2] M. Grätzel, "Photoelectrochemical cells," Nature, vol. 414, no. 6861, pp. 338-344, 2001.

[3] D. Wei, "Dye sensitized solar cells," International Journal of Molecular Sciences, vol. 11, no. 3, pp. 1103-1113, 2010.

[4] M. K. Nazeeruddin, C. Klein, P. Liska, and M. Grätzel, "Synthesis of novel ruthenium sensitizers and their application in dyesensitized solar cells," Coordination Chemistry Reviews, vol. 249, no. 13-14, pp. 1460-1467, 2005.

[5] B. Li, L. Wang, B. Kang, P. Wang, and Y. Qiu, "Review of recent progress in solid-state dye-sensitized solar cells," Solar Energy Materials and Solar Cells, vol. 90, no. 5, pp. 549-573, 2006.

[6] N. Robertson, "Optimizing dyes for dye-sensitized solar cells," Angewandte Chemie, vol. 45, no. 15, pp. 2338-2345, 2006.

[7] A. Sasani, A. Baktash, K. Mirabbaszadeh, and B. Khoshnevisan, "Structural and electronic properties of $\mathrm{Mg}$ and $\mathrm{Mg}-\mathrm{Nb}$ codoped $\mathrm{TiO}_{2}$ (101) anatase surface," Applied Surface Science, vol. 384, pp. 298-303, 2016.

[8] S. E. Gledhill, B. Scott, and B. A. Gregg, "Organic and nanostructured composite photovoltaics: an overview," Journal of Materials Research, vol. 20, no. 12, pp. 3167-3179, 2005.

[9] M. Magni, P. Biagini, A. Colombo, C. Dragonetti, D. Roberto, and A. Valore, "Versatile copper complexes as a convenient springboard for both dyes and redox mediators in dye sensitized solar cells," Coordination Chemistry Reviews, vol. 322, pp. 69-93, 2016.

[10] M. Grätzel, "The advent of mesoscopic injection solar cells," Progress in Photovoltaics: Research and Applications, vol. 14, no. 5, pp. 429-442, 2006.

[11] A. Mishra, M. K. R. Fischer, and P. Büuerle, "Metal-free organic dyes for dye-Sensitized solar cells: from structure: property relationships to design rules," Angewandte Chemie, vol. 48, no. 14, pp. 2474-2499, 2009.

[12] Z. Ning and H. Tian, "Triarylamine: a promising core unit for efficient photovoltaic materials," Chemical Communications, vol. 45, no. 37, pp. 5483-5495, 2009.

[13] S. M. Zakeeruddin and M. Grätzel, "Solvent-free ionic liquid electrolytes for mesoscopic dye-sensitized solar cells," Advanced Functional Materials, vol. 19, no. 14, pp. 2187-2202, 2009.

[14] H. Chang and Y.-J. Lo, "Pomegranate leaves and mulberry fruit as natural sensitizers for dye-sensitized solar cells," Solar Energy, vol. 84, no. 10, pp. 1833-1837, 2010.
[15] G. Zhang, H. Bala, Y. Cheng et al., "High efficiency and stable dye-sensitized solar cells with an organic chromophore featuring a binary $\pi$-conjugated spacer," Chemical Communications, no. 16, pp. 2198-2200, 2009.

[16] A. Torchani, S. Saadaoui, R. Gharbi, and M. Fathallah, "Sensitized solar cells based on natural dyes," Current Applied Physics, vol. 15, no. 3, pp. 307-312, 2015.

[17] H. Zhou, L. Wu, Y. Gao, and T. Ma, "Dye-sensitized solar cells using 20 natural dyes as sensitizers," Journal of Photochemistry and Photobiology A: Chemistry, vol. 219, no. 2-3, pp. 188-194, 2011.

[18] Z.-S. Wang, Y. Cui, K. Hara, Y. Dan-Oh, C. Kasada, and A. Shinpo, "A high-light-harvesting-efficiency coumarin dye for stable dye-sensitized solar cells," Advanced Materials, vol. 19, no. 8, pp. 1138-1141, 2007.

[19] C.-L. Wang, C.-M. Lan, S.-H. Hong et al., "Enveloping porphyrins for efficient dye-sensitized solar cells," Energy and Environmental Science, vol. 5, no. 5, pp. 6933-6940, 2012.

[20] M. J. Griffith, K. Sunahara, P. Wagner et al., "Porphyrins for dyesensitised solar cells: new insights into efficiency-determining electron transfer steps," Chemical Communications, vol. 48, no. 35, pp. 4145-4162, 2012.

[21] W. M. Campbell, A. K. Burrell, D. L. Officer, and K. W. Jolley, "Porphyrins as light harvesters in the dye-sensitised $\mathrm{TiO}_{2}$ solar cell," Coordination Chemistry Reviews, vol. 248, no. 13-14, pp. 1363-1379, 2004.

[22] K. Kudo, H. Yageta, S. Kuniyoshi, and K. Tanaka, "Surface pressure variation in triphenylmethane dye adsorbed merocyanine monolayers at the air-water interface," Japanese Journal of Applied Physics, vol. 32, no. 4, pp. 1775-1778, 1993.

[23] S. Cleinmensen, J. C. Jensen, N. J. Jensen, O. Meyer, P. Olsen, and G. Würtzen, "Toxicological studies on malachite green: a triphenylmethane dye," Archive Für Toxikologie, vol. 56, no. 1, pp. 43-45, 1984.

[24] G. Li, M. Liang, H. Wang et al., "Significant enhancement of open-circuit voltage in indoline-based dye-sensitized solar cells via retarding charge recombination," Chemistry of Materials, vol. 25, no. 9, pp. 1713-1722, 2013.

[25] H. W. Ham and Y. S. Kim, "Theoretical study of indoline dyes for dye-sensitized solar cells," Thin Solid Films, vol. 518, no. 22, pp. 6558-6563, 2010.

[26] X. Ma, J. Hua, W. Wu et al., "A high-efficiency cyanine dye for dye-sensitized solar cells," Tetrahedron, vol. 64, no. 2, pp. 345$350,2008$.

[27] J. Tang, W. Wu, J. Hua, J. Li, X. Li, and H. Tian, "Starburst triphenylamine-based cyanine dye for efficient quasi-solid-state dye-sensitized solar cells," Energy \& Environmental Science, vol. 2, no. 9, pp. 982-990, 2009.

[28] Y. Li, T. Pullerits, M. Zhao, and M. Sun, "Theoretical characterization of the PC60BM:PDDTT model for an organic solar cell," The Journal of Physical Chemistry C, vol. 115, no. 44, pp. 2186521873, 2011.

[29] Ü. Ceylan, G. Ö. Tarı, H. Gökce, and E. Ağar, "Spectroscopic (FT-IR and UV-Vis) and theoretical (HF and DFT) investigation of 2-Ethyl-N-[(5-nitrothiophene-2-yl)methylidene]aniline," Journal of Molecular Structure, vol. 1110, pp. 1-10, 2016.

[30] E. B. Sas, M. Kurt, M. Can, N. Horzum, and A. Atac, "Spectroscopic studies on 9H-carbazole-9-(4-phenyl) boronic acid pinacol ester by DFT method," Journal of Molecular Structure, vol. 1118, pp. 124-138, 2016. 
[31] S. Soleimani Amiri, S. Makarem, H. Ahmar, and S. Ashenagar, "Theoretical studies and spectroscopic characterization of novel 4-methyl-5-((5-phenyl-1,3,4-oxadiazol-2-yl)thio)benzene-1,2diol," Journal of Molecular Structure, vol. 1119, pp. 18-24, 2016.

[32] A. G. Al-Sehemi, A. Irfan, A. M. Asiri, and Y. A. Ammar, "Synthesis, characterization and DFT study of methoxybenzylidene containing chromophores for DSSC materials," Spectrochimica Acta Part A: Molecular and Biomolecular Spectroscopy, vol. 91, pp. 239-243, 2012.

[33] N. T. R. N. Kumara, M. R. R. Kooh, A. Lim et al., "DFT/TDDFT and experimental studies of natural pigments extracted from black tea waste for DSSC application," International Journal of Photoenergy, vol. 2013, Article ID 109843, 8 pages, 2013.

[34] A. S. Beni and M. Zarandi, "Application of DFT and MP2 calculations on structural and water-assisted proton transfer in 3-amino-4-nitrofurazan," Russian Journal of Physical Chemistry A, vol. 90, no. 2, pp. 374-382, 2016.

[35] R. M. El-Shishtawy, S. A. Elroby, A. M. Asiri, and K. Mullen, "Optical absorption spectra and electronic properties of symmetric and asymmetric squaraine dyes for use in DSSC solar cells: DFT and TD-DFT studies," International Journal of Molecular Sciences, vol. 17, no. 4, p. 487, 2016.

[36] C. F. Sun, Y. Z. Li, D. W. Qi, H. X. Li, and P. Song, "Optical and electrical properties of purpurin and alizarin complexone as sensitizers for dye-sensitized solar cells," Journal of Materials Science: Materials in Electronics, vol. 27, no. 8, pp. 8027-8039, 2016.

[37] Y. Z. Li, C. F. Sun, D. W. Qi, P. Song, and F. C. Ma, "Effects of different functional groups on the optical and charge transport properties of copolymers for polymer solar cells," RSC Advances, vol. 6, no. 66, pp. 61809-61820, 2016.

[38] P. Song, Y. Li, F. Ma, T. Pullerits, and M. Sun, "Photoinduced electron transfer in organic solar cells," Chemical Record, vol. 16, no. 2, pp. 734-753, 2016.

[39] W. Kohn and L. J. Sham, "Quantum density oscillations in an inhomogeneous electron gas," Physical Review, vol. 137, no. 6, pp. A1697-A1705, 1965.

[40] C. Lee, W. Yang, and R. G. Parr, "Development of the ColleSalvetti correlation-energy formula into a functional of the electron density," Physical Review B: Condensed Matter, vol. 37, no. 2, pp. 785-789, 1988.

[41] D. A. Kleinman, "Nonlinear dielectric polarization in optical media," Physical Review, vol. 126, no. 6, pp. 1977-1979, 1962.

[42] M. J. Frisch, G. W. Trucks, H. B. Schlegel et al., Gaussian 09, Gaussian Inc., Wallingford, Conn, USA, 2009.

[43] S. Kushwaha and L. Bahadur, "Enhancement of power conversion efficiency of dye-sensitized solar cells by co-sensitization of Phloxine B and Bromophenol blue dyes on $\mathrm{ZnO}$ photoanode," Journal of Luminescence, vol. 161, pp. 426-430, 2015.

[44] W. Li, J. Wang, J. Chen, F.-Q. Bai, and H.-X. Zhang, "Theoretical investigation of triphenylamine-based sensitizers with different $\pi$-spacers for DSSC," Spectrochimica Acta Part A: Molecular and Biomolecular Spectroscopy, vol. 118, pp. 1144-1151, 2014.

[45] M. Liang and J. Chen, "Arylamine organic dyes for dyesensitized solar cells," Chemical Society Reviews, vol. 42, no. 8, pp. 3453-3488, 2013.

[46] S. Rühle, M. Greenshtein, S.-G. Chen et al., "Molecular adjustment of the electronic properties of nanoporous electrodes in dye-sensitized solar cells," The Journal of Physical Chemistry B, vol. 109, no. 40, pp. 18907-18913, 2005.
[47] Z. Ning, Y. Fu, and H. Tian, "Improvement of dye-sensitized solar cells: what we know and what we need to know," Energy \& Environmental Science, vol. 3, no. 9, pp. 1170-1181, 2010.

[48] J. Preat, D. Jacquemin, and E. A. Perpète, “Towards new efficient dye-sensitised solar cells," Energy and Environmental Science, vol. 3, no. 7, pp. 891-904, 2010.

[49] T. Marinado, D. P. Hagberg, M. Hedlund et al., "Rhodanine dyes for dye-sensitized solar cells: spectroscopy, energy levels and photovoltaic performance," Physical Chemistry Chemical Physics, vol. 11, no. 1, pp. 133-141, 2009.

[50] J. Preat, C. Michaux, D. Jacquemin, and E. A. Perpète, "Enhanced efficiency of organic dye-sensitized solar cells: triphenylamine derivatives," Journal of Physical Chemistry C, vol. 113, no. 38, pp. 16821-16833, 2009.

[51] J. B. Asbury, Y.-Q. Wang, E. Hao, H. N. Ghosh, and T. Lian, "Evidences of hot excited state electron injection from sensitizer molecules to $\mathrm{TiO}_{2}$ nanocrystalline thin films," Research on Chemical Intermediates, vol. 27, no. 4-5, pp. 393-406, 2001.

[52] R. Katoh, A. Furube, T. Yoshihara et al., "Efficiencies of electron injection from excited $\mathrm{N}_{3}$ dye into nanocrystalline semiconductor $\left(\mathrm{ZrO}_{2}, \mathrm{TiO}_{2}, \mathrm{ZnO}, \mathrm{Nb}_{2} \mathrm{O}_{5}, \mathrm{SnO}_{2}, \mathrm{In}_{2} \mathrm{O}_{3}\right)$ Films," Journal of Physical Chemistry B, vol. 108, no. 15, pp. 4818-4822, 2004.

[53] G. Olbrechts, T. Munters, K. Clays, A. Persoons, O.-K. Kim, and L.-S. Choi, "High-frequency demodulation of multi-photon fluorescence in hyper-Rayleigh scattering," Optical Materials, vol. 12, no. 2, pp. 221-224, 1999.

[54] C.-R. Zhang, L. Liu, J.-W. Zhe et al., "The role of the conjugate bridge in electronic structures and related properties of tetrahydroquinoline for dye sensitized solar cells," International Journal of Molecular Sciences, vol. 14, no. 3, pp. 5461-5481, 2013.

[55] T. Le Bahers, T. Pauporté, G. Scalmani, C. Adamo, and I. Ciofini, "A TD-DFT investigation of ground and excited state properties in indoline dyes used for dye-sensitized solar cells," Physical Chemistry Chemical Physics, vol. 11, no. 47, pp. 11276-11284, 2009. 

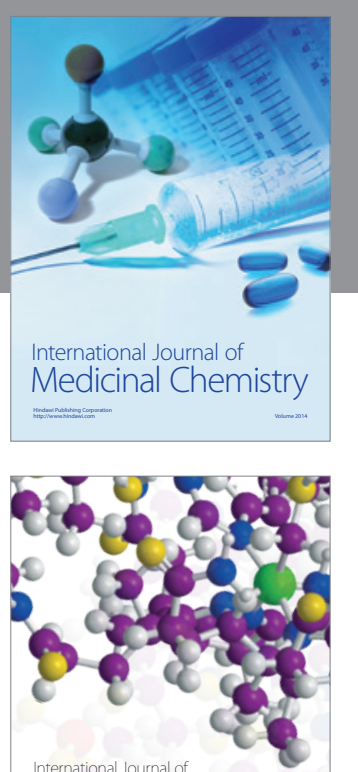

Carbohydrate Chemistry

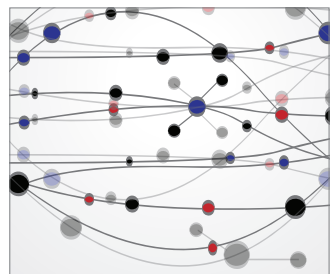

The Scientific World Journal
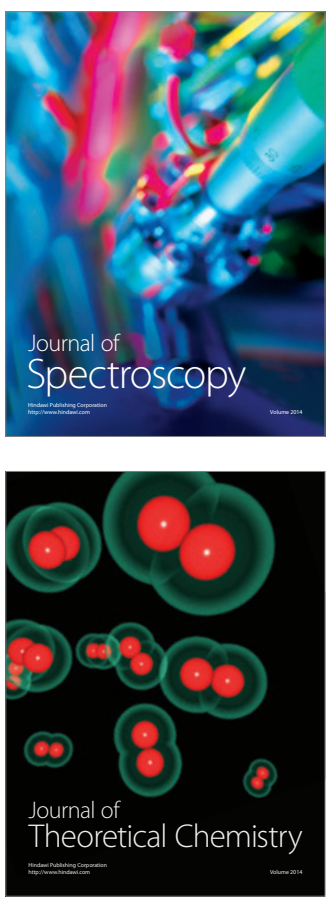
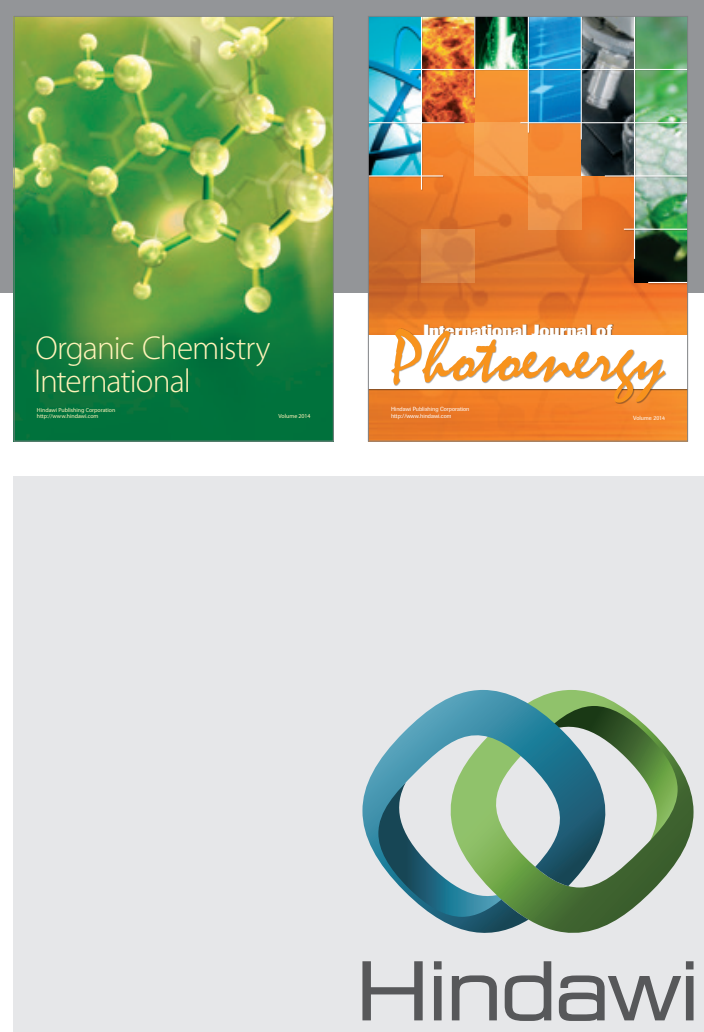

Submit your manuscripts at

http://www.hindawi.com

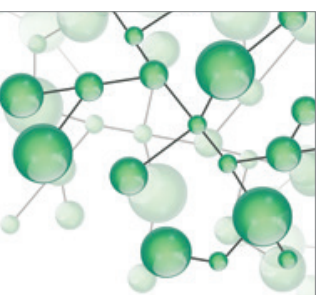

International Journal of

Inorganic Chemistry

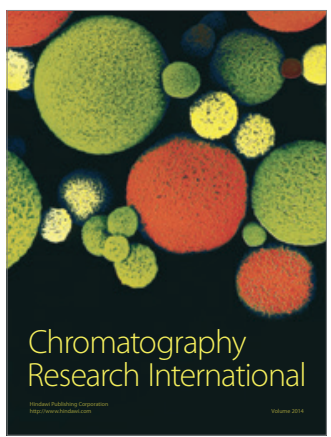

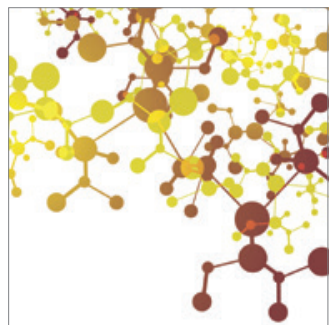

Applied Chemistry
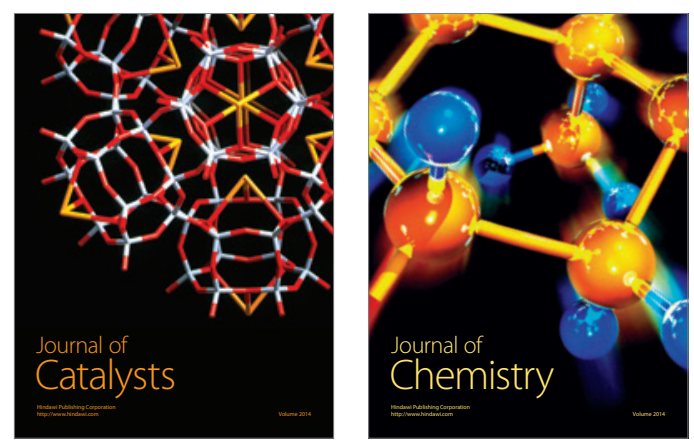
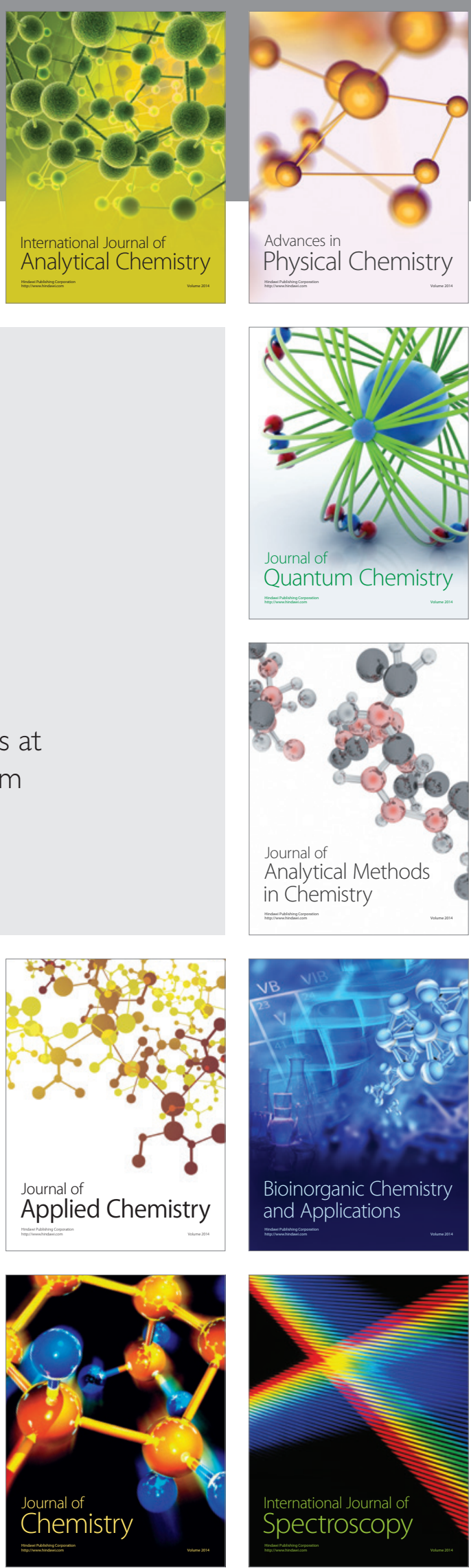